\title{
Research Paper: Immune Checkpoint Molecules in Primary Diffuse Large B-Cell Lymphoma of the Central Nervous System
}

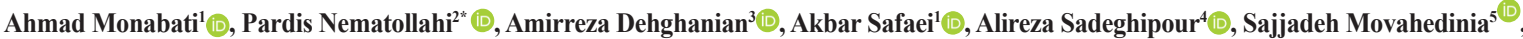 \\ Maral Mokhtari ${ }^{6}$ (1)
}

1. Department of Pathology, Hematology Research Center, School of Medicine, Shiraz University of Medical Science, Shiraz, Iran

2. Department of Pathology, Cancer Prevention Research Center, Isfahan University of Medical Science, Isfahan, Iran.

3. Department of Pathology, Molecular Pathology and Cytogenetics Division, School of Medicine, Shiraz University of Medical Science, Shiraz, Iran

4. Department of Pathology, Oncopathology Research Center, Iran University of Medical Sciences, Tehran, Iran.

5. Department of Pathology, Faculty of Medicine, Kerman University of Medical Science, Kerman, Iran.

6. Department of Pathology, School of Medicine, Shiraz University of Medical Sciences, Shiraz, Iran.

\begin{tabular}{|c|c|}
\hline \multirow{2}{*}{$\begin{array}{l}\text { Use vour device to scan } \\
\text { and read the article online }\end{array}$} & \\
\hline & Citation: Monabati, A., Nematollahi, P., Dehghanian, A., Safaei, A., Sadeghipour, A., \& Movahedinia, S., et al. Immune \\
\hline $4 h+4$ & $\begin{array}{l}\text { Checkpoint Molecules in Primary Diffuse Large B-Cell Lymphoma of the Central Nervous System. Basic and Clinical Neurosci- } \\
\text { ence, 11(4), 491-498. http://dx.doi.org/10.32598/bcn.11.4.2542.1 }\end{array}$ \\
\hline 口ithos & doil' http://dx.doi.org/10.32598/ben.11.4.2542.1 \\
\hline
\end{tabular}

\section{(c) (1) (s)}

Article info:

Received: 05 May 2020

First Revision: 08 May 2020

Accepted: 17 May 2020

Available Online: 01 Jul 2020

Keywords:

Primary large B-cell lymphoma, CNS, Immune checkpoint, Programmed death-1 (PD-1), Programmed death-1 ligand (PD-L1),

Central nervous system

\begin{abstract}
A B S T RA C T
Introduction: Primary Diffuse Large B Cell Lymphoma of CNS (PCNSL) is a rare variant of Diffuse Large B Cell Lymphoma (DLBCL) and presents with an aggressive clinical course and usually resistant to commonly used therapy regimens. Recently, role of immune checkpoint molecules including PD-1 and PD-L1 confirmed in some solid tumors and lymphoma resulting tumor cells escape the immune system and help to survive and to spread. Inhibitors of PD-1 and PD-L1 have shown lasting responses in several solid and some hematological tumors, while limited studies evaluate checkpoint molecules on PCNSL.
\end{abstract}

Method: In this study, we investigated PD-1 and PD-L1 expression by immunostaining on 71 patients with PCNSL and correlation with demographic data, location of the tumor, proliferation rate, cell of origin, and CD8 positive T cell infiltration in tumor microenvironment.

Results: 16 from71 showed PD-1 expression, while PD-L1 expression were 42/71. No association was determined between PD-1/PD-L1 expression and gender, cell of origin, and proliferation rate, but a highly significant difference was determined between the infiltration of $\mathrm{CD} 8$ positive $\mathrm{T}$ cells in two groups of $\mathrm{PD}-1 / \mathrm{PD}-\mathrm{L} 1$ positive and negative.

Conclusion: This study revealed expression of check point molecules in remarkable number of PCNSL which may open new therapeutic recommendations in this aggressive lymphoma type. 


\section{Highlights}

- Primary diffuse large B-cell lymphoma of the central nervous system (PCNSL) is a rare variant of Diffuse large B-cell lymphoma limited to the central nervous system.

- PCNSL has a poor prognosis without response to usual therapy for other types of lymphoma.

- Checkpoint molecules have a critical role in the pathogenicity of some malignancies.

- Few research studies have been conducted about the Programmed Death-1 (PD-1) and its ligand PD-L1 (checkpoint molecules) role in the pathogenicity of PCNSL.

- PD-1 and PD-L1 have been detected in some PCNSLs and show association with T cell infiltration.

\section{Plain Language Summary}

Primary diffuse large B-cell lymphoma of the central nervous system (PCNSL) is a rare variant of high-grade lymphoma of the brain which is limited to immune-privileged organs such as the central nervous system, testis, and eyes. This type of high-grade lymphoma is resistant to usual therapy of other similar lymphomas and shows poor prognosis. Immunotherapy and immune checkpoint (programmed death-1 [PD-1] and its ligand PD-L1) inhibitors are new treatment protocols and their use was approved in some solid tumors and few types of lymphoma, including classical Hodgkin lymphoma. However, few research studies have been done on the evaluation of immune checkpoint molecules in the pathogenesis of PCNSL. We investigated these molecules on 71 patients with PCNSL by immunostaining method and noticed the expression of PD-1 and PD-L1 in some of them. This study and similar ones open new therapeutic routes in this aggressive lymphoma type.

\section{Introduction}

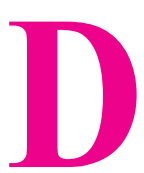

iffuse Large B-Cell Lymphoma (DLBCL) is a neoplasm of medium to large $B$ cells and often involves multiple nodal and extranodal regions, whereas some DLBCL variants, including primary diffuse large $\mathrm{B}$-cell lymphoma of the central nervous system (PCNSL), Primary Testicular Lymphoma (PTL), and primary mediastinal large B-cell lymphoma (PMBL), present as localized masses in extranodal specific organs. PCNSL is a rare neoplasm and originates from the brain, spinal cord, leptomeninges, or eye, with no evidence of systemic disease (Nayak et al., 2017). DLBCLs are classified based on molecular characteristics to germinal center B-cell subtype (GCB) and activated B-cell subtype (ABC). Most PCNSLs show an ABC-subtype phenotype and many studies claim that they originate from a late germinal center or early-post germinal center cell (Yang \& Liu, 2017). This specific type of DLBCL accompanies with PTL, has restricted homing to the main immune sanctuaries, has poor survival, and is usually refractory to commonly-used therapy regimens (Chapuy et al., 2016) such as high-dose chemotherapy with methotrexate, rituximab, or whole-brain radiotherapy, and bone marrow transplantation (Berghoff et al., 2014; Korfel \& Schlegel,
2013). Most patients represent with relapse, and there is limited knowledge of effective therapy (Berghoff et al., 2014). New treatment protocols such as immunotherapy, including monoclonal receptor T-cell therapies, and immune checkpoint inhibitors improve the efficacy of chemoradiotherapy in the treatment of malignancies.

One of the most frequently-studied pathways in immunotherapy is the programmed death-1 receptor (PD-1, CD279) and its ligands PD-L1 (CD274), which has a major role in a variety of neoplastic diseases. PD-1 is expressed by some T cells, B cells, and Natural Killer (NK) cells, and has been diagnosed as an exhaustion marker in some cancer cells (Turnis, Andrews, \& Vignali, 2015). PD-L1 (CD274) is also expressed at the surface of some B cells, T cells, macrophages, and antigen-presenting cells and on some malignant cells, including a variety of lymphomas. PD-1 and its ligand suppress the immune system and promote the escape of tumor cells from the immune response (Berghoff et al., 2014; Panjwani, Charu, DeLisser, Molina-Kirsch, Natkunam, \& Zhao, 2018). In many solid tumors, PD-1 is upregulated by a large proportion of Tumor-Infiltrating Lymphocytes (TILs), whereas its ligands PD-L1 and PD-L2 are expressed by tumor cells (Ahmadzadeh et al., 2009). Binding of PD-L1 to PD-1 inhibits the proliferation of activated $\mathrm{T}$ lymphocytes and so creates 
the anti-tumor immune response. Several lymphoma types express PD-1 and PD-L1, including mycosis fungoides, Sezary syndrome, nodular sclerosis, mixed cellularity classical Hodgkin's lymphoma, primary mediastinal large B-cell lymphoma, T-cell/histiocyte-rich B-cell lymphoma, EBVpositive and -negative post-transplant lymphoproliferative disorder, EBV-associated DLBCL, plasmablastic lymphoma, extranodal NK/T-cell lymphoma, and primary effusion lymphoma (Chen et al., 2013; Kantekure et al., 2012). Inhibitors of PD-1 (nivolumab) and PD-L1 (pembrolizumab) disrupt this signaling and have shown lasting responses in several solid and some hematological tumors (Brahmer et al., 2012; Callahan \& Wolchok, 2013; Gatalica et al., 2014; Wolchok et al., 2013). These medications also improve the outcomes of patients with relapsed/refractory Classical Hodgkin Lymphoma (CHL) and Chronic Lymphocytic Leukemia (CLL), so they provide treatment opportunities in other hematopoietic malignancies (Ansell et al., 2015; Ding et al., 2017).

Recently a few studies evaluated the expression of checkpoint molecules and its ligands on lymphoid malignancies, including B, T, NK cells, and histiocytic neoplasms. In one comprehensive study, a total of 702 patients with various types of lymphomas and histiocytic malignancies were investigated and expression of PD-1, PD-L1, and PD-L2 was evaluated with the immunostaining method. PD-L1 was detected in $80 \%$ of anaplastic large cell lymphoma, angioimmunoblastic T-cell lymphoma, and follicular dendritic cell sarcoma; 75\% of nodular lymphocyte-predominant Hodgkin lymphoma; $53 \%$ of primary mediastinal large B-cell lymphoma; $39 \%$ of extranodal NK/T cell lymphoma; $26 \%$ of peripheral T-cell lymphoma; $10 \%$ of diffuse large B-cell lymphoma; and barely in mantle, marginal zone, and small lymphocytic lymphomas (Panjwani et al., 2018). Few studies have been conducted on the PD-1/PD-L1 activation in the pathophysiology of PCNSL (Berghoff et al., 2014). We presume that immunosuppression caused by PD-1/PD-L1 activation may have an effective role in PCNSL pathobiology and so the immunotherapy against these molecules may improve patients' survival. Nevertheless, treatment with checkpoint inhibitors is costly and also associated with toxicities, moreover only some groups of patients benefit from these treatments (Atanackovic \& Luetkens, 2018). Nowadays, the question is why a significant number of patients are intrinsically resistant to these therapies. To address this question, we are searching for predictive biomarkers indicating the effectiveness of these therapies. Recent studies have shown that PD-1 blockade selectively increases CD8 memory T cell numbers within the tumor microenvironment. This infiltration increases therapeutic efficacy. For example, tumor regression correlates with the increase of this population following treatment in patients with melanoma who have PD-1 $\mathrm{CD} 8$ positive $\mathrm{T}$ cells in the microenvironment of tumors before the treatment. Tumor infiltration with PD-1 high and $\mathrm{CD} 8$ positive $\mathrm{T}$ cells has been proposed as an accurate predictor of responses to anti-PD-1 therapy in melanoma. For this reason, the evaluation of CD8 $\mathrm{T}$ cell infiltration in the tumor may be used as a biomarker for therapeutic efficacy (Edwards et al., 2018; Zuazo et al., 2017). We propose that the immune profile of microenvironment cells in tumors before treatment could shed light on the strategies for the efficacy of checkpoint inhibitor regimens.

\section{Materials and Methods}

In this retrospective cross-sectional study, formalin-fixed and paraffin-embedded tumor tissue of surgical resections or stereotactic biopsies of 71 patients with PCNSL between 2004 and 2018 were selected from archives of Shiraz, and Tehran medical university hospitals, Shiraz and Tehran cities, Iran. The patients with a history of systemic lymphoma, immune-deficiency, and under corticosteroid therapy before biopsy (for tumor shrinkage following corticosteroid therapy) were excluded from the study. Three tissue microarrays are made from duplicate or triplicate 1-mm cores of blocks. Histomorphological subtyping was performed on hematoxylin and eosin (H\&E) sections according to the fourth edition of the WHO classification of hematopoietic and lymphoid neoplasms. Lymphoma cells may be scarce or compact and accumulate in perivascular spaces (Figure 1).

Immunophenotyping, clinical, imaging, and demographic data were filled in the prepared table. The following antibodies were used after antigen retrieval according to the manufacturer's instructions: CD20 (clone L26, Master Diagnóstica, Spain), CD10 (clone 56C6, Master Diagnóstica, Spain), BCL6 (clone LN22, Master Diagnóstica, Spain), MUM1 (clone MUM1p, Master Diagnóstica, Spain), PD-1 (clone NAT105, Master Diagnóstica, Spain), PD-L1 (clone CAL10, Master Diagnóstica, Spain), CD3 (clone EP41, Master Diagnóstica, Spain), CD4 (clone EP204, Master Diagnóstica, Spain), CD8 (clone SP16, Master Diagnóstica, Spain), and Ki-67 (clone SP6, Master Diagnóstica, Spain). The cell of origin was determined by estimating protein expression in tumoral cells using IHC in 30\% cut-off for CD10, BCL6, MUM1 based on the Hans algorithm (Jaffe, Arber, Campo, Harris, \& Quintanilla-Fend, 2016). We used the placenta for PD-L1 and lymph node for PD-1 as positive controls. We evaluated the expression of PD-1 and or PDL-1 on tumor cells, Tumor-Infiltrating Lymphocytes (TILs), and TumorAssociated Macrophages (TAMs). Immunohistochemistry was evaluated semi-quantitatively with a light microscope by two authors who were blinded to any clinical data on a multiheaded microscope. For both PD-1 and PD-L1, strong, and fully membranous immunoreactivity on more than $\sim 5 \%$ of any cell type was considered positive (Figure 2). The cut-off 


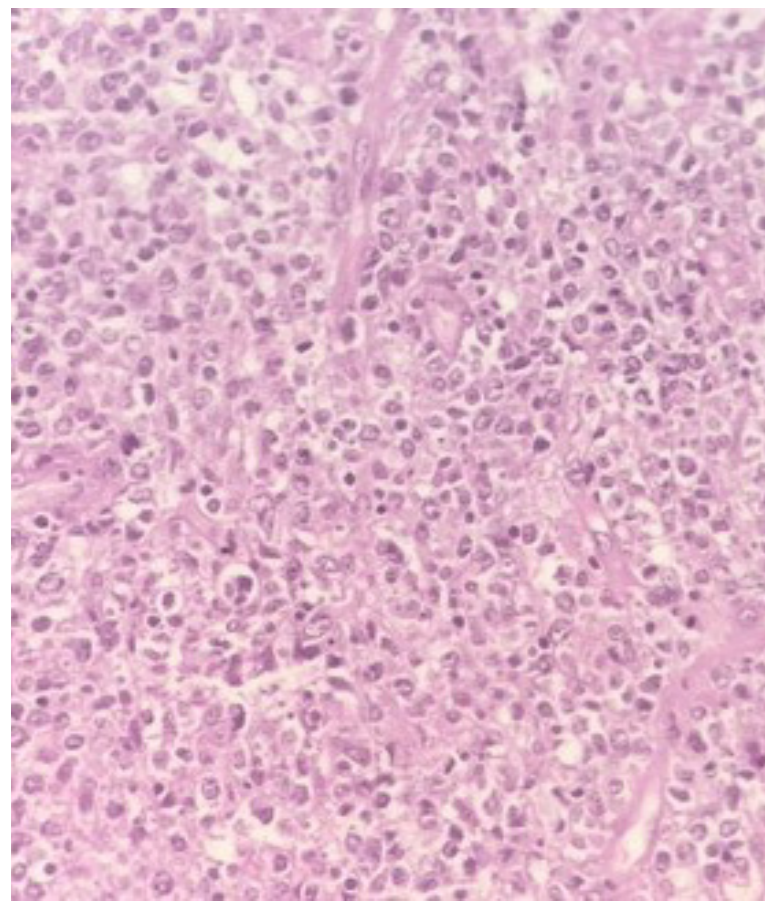

NEUR:SCIENCE

Figure 1. Primary diffuse large B cell lymphoma of CNS. Proliferation of tumor cells as solid and some accumulation in perivascular space. X400

point of 5\% was chosen based on previous research (Berghoff et al., 2014). The density of PD-1 and PD-L1 positive cells should be evaluated in non-necrotic tissue areas and are scored as follows: low density, scattered cells; moderate density, loose but widespread infiltration; high density, dense and widespread infiltration (Berghoff et al., 2014). For the quantification of intratumoral cytotoxic lymphocytes, we quantified anti-CD8 immunostained cells in a total area of $1 \mathrm{~mm}^{2}$. For this purpose, we counted 4 microscopic fields (x400) (each sized $0.25 \mathrm{~mm}^{2}$ ) showing non-necrotic compact tumor infiltrates. In each field, all anti-CD8 immunostained cells were counted manually. Finally, the median number of infiltrating CD8 cytotoxic lymphocytes was calculated and the patients were classified as two groups of higher and lower than the median. The patients were also classified into two groups according to Ki-67 immunostaining proliferation rate to equal or more than $70 \%$ and less than $70 \%$ mitosis (Preusser et al., 2010).

\section{Results}

We studied 71 confirmed cases of PCNSL, 42 men and 29 women, aged between 7 and 81 years (mean age: 55.6 years and median age: 58 years). Most of the tumors were located in the supratentorial region (55.71\%). Locations of tumors were as follows: frontal lobe, $14.71 \%$;

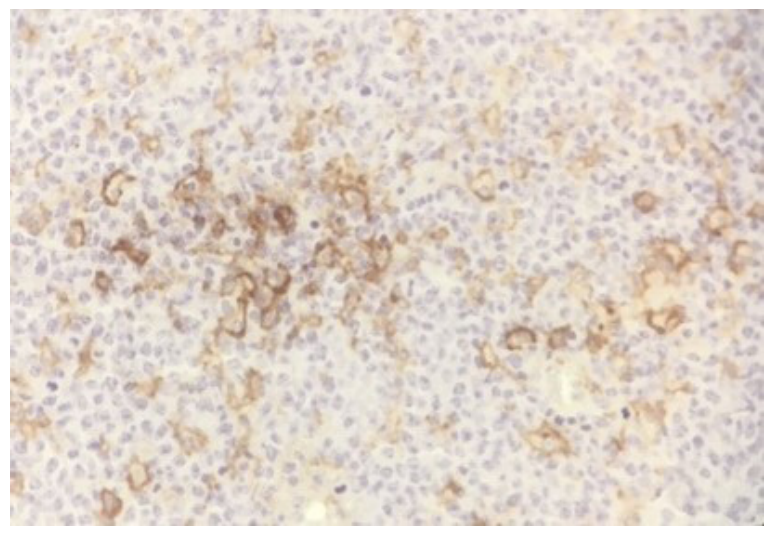

Figure 2. Fully membranous immunoreactivity of PDL-1 by immunohistochemistry. X400 
temporal lobe, $11.71 \%$; parietal lobe, 5.71\%; occipital lobe, $1.71 \%$; multiple lesions of the cortex, 3.71\%; periventricular area, $3.71 \%$; cerebellum, 5.71\%; spinal cord, $8.71 \%$; meninges, $3.71 \%$; multiple lesions of brain lobes, $5.71 \%$; and brain NOS, $13.71 \%$. About $57.71 \%$ of tumors showed non-germinal center B cell origin. The proliferation rate was between $10 \%$ and $95 \%$; in 48 patients it was equal or more than $70 \%$; in 23 patients, it was less than $70 \%$. Infiltration of $\mathrm{CD} 8$ positive $\mathrm{T}$ cells were less than $10 / \mathrm{mm}^{2}$ to $1400 / \mathrm{mm}^{2}$ with the median of $35 / \mathrm{mm} 2$. About $16.71 \%$ showed PD-1 expression on TIL while PD-L1 expression on TIL, TAM, and or tumor cells were $42.71 \%$ (Table 1 ).

We used the $t$ test for the evaluation of the relationship between age and expression of PD-1/PD-L1. There was no association between age and PD-1/PD-L1 expression. The Chisquare test was used for checking the relationship between expression of PD-1/PD-L1 with gender, location, cell of origin, proliferation rate, and CD8 positive T-cell infiltration. There was also no association between PD-1 expression and gender or cell of origin. PD-1 expression decreased in tumors with a high proliferation rate but statistically, this association was not significant. No association was determined between PD-L1 expression and gender, cell of origin, or proliferation rate, but a highly significant difference was observed between the infiltration of CD8 positive T cells between two groups of PD-1/PD-L1 positive and negative (Tables 2 and 3).

\section{Discussion}

Primary CNS lymphoma is a rare lymphoma with an aggressive clinical course and poor response to current therapies. Biologic studies of PCNSL are challenging because of the rarity of the disease. So little is known about the role of immune checkpoints in the pathogenesis of PCNSL and impact on tumor aggressive course (Berghoff et al., 2014; Chapuy et al., 2016; Nayak et al., 2017; Panjwani et al., 2018;

Table 1. Summary of the patients' characteristics and results of immunohistochemical analyses

\begin{tabular}{|c|c|c|}
\hline \multicolumn{2}{|c|}{ Parameters } & \multirow{2}{*}{$\begin{array}{l}\text { No. (\%) } \\
37(52.1) \\
34(47.9)\end{array}$} \\
\hline Age at operation & $\begin{array}{l}<60 y \\
\geq 60 y\end{array}$ & \\
\hline \multirow{11}{*}{ Localization } & Frontal & 14 (19.7) \\
\hline & Temporal & 11 (15.5) \\
\hline & Parietal & $5(7)$ \\
\hline & Occipital & $1(1.4)$ \\
\hline & Multiple lesion of cortex & $3(4.2)$ \\
\hline & Periventricular & $3(4.2)$ \\
\hline & Cerebellum & $5(7)$ \\
\hline & Spinal cord & $8(11.2)$ \\
\hline & Meninges & $3(4.2)$ \\
\hline & Multifocal & $5(7)$ \\
\hline & Brain NOS & $13(18.3)$ \\
\hline \multirow{2}{*}{ Cell of origin } & GC (Germinal Cell) type & 14 (19.7) \\
\hline & ABC (Activated B-cell) type & $57(80.3)$ \\
\hline \multirow{2}{*}{ Gender } & Male & $42(59.2)$ \\
\hline & Female & $29(40.8)$ \\
\hline \multirow{2}{*}{ Proliferation rate } & $<70 \%$ & $23(32.4)$ \\
\hline & $\geq 70 \%$ & $48(67.6)$ \\
\hline \multirow{2}{*}{ PD-1 expression } & Negative & 55 (77.5) \\
\hline & Positive & $16(22.5)$ \\
\hline \multirow{2}{*}{ PD-L1 expression } & Negative & $29(40.9)$ \\
\hline & Positive & $42(59.1)$ \\
\hline \multirow{2}{*}{$\begin{array}{l}\text { Number of intra } \\
\text { tumoral cytotoxic lymphocytes }\end{array}$} & $<$ median & $36(50.7)$ \\
\hline & $\geq$ median & 35 (49.3) \\
\hline
\end{tabular}


Table 2. Association of PD-1 with demographic data, proliferation rate, cell of origin and CD8 positive T-cell infiltration

\begin{tabular}{|c|c|c|c|c|c|}
\hline \multicolumn{3}{|c|}{ Variables } & \multirow{2}{*}{$\begin{array}{c}\text { Patients With PD-1 } \\
\begin{array}{c}(+) \text { Cells }(\mathbf{n}=16) \\
9 \\
7\end{array}\end{array}$} & \multirow{2}{*}{$\begin{array}{c}\text { Patients With PD-1 } \\
\begin{array}{c}(-) \text { Cells }(\mathbf{n}=\mathbf{5 5}) \\
33 \\
22\end{array}\end{array}$} & \multirow{2}{*}{$\begin{array}{c}\mathbf{P} \\
0.788\end{array}$} \\
\hline $\begin{array}{l}\text { Male } \\
\text { Female }\end{array}$ & & $\begin{array}{l}42 \\
29\end{array}$ & & & \\
\hline $\begin{array}{l}\text { Germinal cell ty } \\
\text { Activated B-cell } t\end{array}$ & & $\begin{array}{l}14 \\
57\end{array}$ & $\begin{array}{c}2 \\
11\end{array}$ & $\begin{array}{l}12 \\
46\end{array}$ & 0.727 \\
\hline Proliferation rate & $\begin{array}{l}<70 \\
\geq 70\end{array}$ & $\begin{array}{l}23 \\
48\end{array}$ & $\begin{array}{l}9 \\
7\end{array}$ & $\begin{array}{l}14 \\
41\end{array}$ & 0.063 \\
\hline $\begin{array}{l}\text { Number of intratumoral cytotoxic } \\
\text { lymphocytes }\end{array}$ & $\begin{array}{l}<\text { median } \\
\geq \text { median }\end{array}$ & $\begin{array}{l}36 \\
35\end{array}$ & $\begin{array}{c}4 \\
12\end{array}$ & $\begin{array}{l}32 \\
23\end{array}$ & 0.019 \\
\hline
\end{tabular}

Table 3. Association of PD-L1 with demographic data, proliferation rate, cell of origin and CD8 positive T-cell infiltration

\begin{tabular}{|c|c|c|c|c|c|}
\hline \multicolumn{3}{|c|}{ Variables } & \multirow{2}{*}{$\begin{array}{c}\text { Patients With PD-L1 } \\
\begin{array}{c}(+) \text { Cells }(\mathbf{n}=\mathbf{4 2}) \\
24 \\
18\end{array}\end{array}$} & \multirow{2}{*}{$\begin{array}{c}\text { Patients With PD- } \\
\text { L1 (-) Cells }(\mathbf{n}=\mathbf{2 9}) \\
18 \\
11\end{array}$} & \multirow{2}{*}{$\begin{array}{c}\mathbf{P} \\
0.678\end{array}$} \\
\hline $\begin{array}{l}\text { Male } \\
\text { Female }\end{array}$ & & $\begin{array}{l}42 \\
29\end{array}$ & & & \\
\hline $\begin{array}{l}\text { Germinal cell } \\
\text { Activated B-ce }\end{array}$ & & $\begin{array}{l}14 \\
57\end{array}$ & $\begin{array}{c}5 \\
25\end{array}$ & $\begin{array}{c}9 \\
32\end{array}$ & 0.211 \\
\hline Proliferation rate & $\begin{array}{l}<70 \% \\
\geq 70 \%\end{array}$ & $\begin{array}{l}23 \\
48\end{array}$ & $\begin{array}{c}9 \\
20\end{array}$ & $\begin{array}{l}14 \\
28\end{array}$ & 0.862 \\
\hline $\begin{array}{l}\text { Number of intratumoral cyto- } \\
\text { toxic lymphocytes }\end{array}$ & $<$ median & $\begin{array}{l}36 \\
35\end{array}$ & $\begin{array}{l}14 \\
28\end{array}$ & $\begin{array}{c}22 \\
7\end{array}$ & 0.000 \\
\hline
\end{tabular}

NEUR SCIENCE

Yang \& Liu, 2017). The expression of PD-1 and PD-L1 has recently been found in several lymphoma types (Berghoff et al., 2014). PD-L1 expression was detected in a high percentage of anaplastic large cell lymphoma, angioimmunoblastic T-cell lymphoma, follicular dendritic cell sarcoma, nodular lymphocyte-predominant Hodgkin lymphoma, primary mediastinal large B-cell lymphoma, only $10 \%$ of diffuse large B-cell lymphoma, and barely in mantle, marginal zone, and small lymphocytic lymphomas (Panjwani et al., 2018). In a study by Berghoff AS et al., PD-1 and or PDL1 were seen on tumor cells, TILs, or TAMs, TAMs in a total of $18 / 20(90 \%)$ of cases, only $10 \%$ of PCNSL cases $(n=2 / 20)$ were found to have PD-L1+ tumor cells. PD-L1 expression on intratumoral TAMs was found in 4/20 (20\%) tumors and 12/20 (60\%) cases; intratumoral PD-1 positive TIL was present (Berghoff et al., 2014). A study on PCNSL by Miyasato Y demonstrated no PD-L1 expression by immunohistochemistry on lymphoma cells while PD-L1 expression on TAMs was seen in 3 out of 5 cases (Miyasato et al., 2018). In another study by Melissa Alame et al. in France, PD-L1 protein expression by the neoplastic B cells was observed in 17.5\% (10/57) of PCNSL cases (Alame et al., 2019). In this study, we found $29 \%$ (16/71) PD-1 expression on TILs and TAMs, as well as, 76.4\% (42/71) PD-L1 expression on TILs, TAMs, and tumor cells in PCNSL. Also, 27 out of 71 patients were neg- ative for both PD-1 and PD-L1. Nevertheless, checkpoint inhibitors therapies are also associated with side effects and are expensive. Besides, only some groups of patients benefit from these treatments (Atanackovic \& Luetkens, 2018). It remains largely unknown why a significant number of patients are intrinsically resistant to these therapies and limited studies considered predictive biomarkers for these therapies. A few studies observed that CD8 T cell infiltration may be used as a biomarker for therapeutic efficacy in some solid tumors (Edwards et al., 2018; Zuazo et al., 2017). In this study, infiltration of CD8 positive T cells were also evaluated by immunostaining as a message for informing strategies for immune checkpoint blockade therapies.

\section{Conclusion}

Our study offers novel insight into the immunosuppressive identity of checkpoint molecules in PCNSL and may open new therapeutic recommendations in this aggressive lymphoma type. However, in all cases, some variants, including alterations in background inflammatory cells probably affect the therapeutic efficacy and expected outcomes. 


\section{Ethical Considerations}

\section{Compliance with ethical guidelines}

This article does not contain any studies with direct human participants' involvement by any of the authors.

Funding

The study was funded by a grant ( No. 98-01-49-20015) provided by Shiraz University of Medical Sciences.

\section{Authors' contributions}

All authors contributed equally in preparing all parts of the research.

\section{Conflict of interest}

The authors declared no conflict of interest.

\section{Acknowledgments}

All the authors would like to express their gratitude to Pathology Staffs at Faghihi Hospital, Shiraz, Iran.

\section{References}

Ahmadzadeh, M., Johnson, L. A., Heemskerk, B., Wunderlich, J. R., Dudley, M. E., \& White, D. E., et al. (2009). Tumor antigenspecific CD8 T cells infiltrating the tumor express high levels of PD-1 and are functionally impaired. Blood, The Journal of the American Society of Hematology, 114(8), 1537-44. [DOI:10.1182/ blood-2008-12-195792]

Alame, M., Pirel, M., Costes-Martineau, V., Bauchet, L., Fabbro, M., \& Tourneret, A., et al. (2019). Characterisation of tumour microenvironment and immune checkpoints in primary central nervous system diffuse large B cell lymphomas. Virchows Archiv, 476, 891-902. [DOI:10.1007/s00428-019-02695-6] [PMID]

Ansell, S. M., Lesokhin, A. M., Borrello, I., Halwani, A., Scott, E. C., \& Gutierrez, M., et al. (2015). PD-1 blockade with nivolumab in relapsed or refractory Hodgkin's lymphoma. New England Journal of Medicine, 372(4), 311-9. [DOI:10.1056/NEJMoa1411087] [PMID] [PMCID]

Atanackovic, D., \& Luetkens, T. (2018). Biomarkers for checkpoint inhibition in hematologic malignancies. Seminars in Cancer Biology, 52(2), 198-206. [DOI:10.1016/j.semcancer.2018.05.005] [PMID]

Berghoff, A. S., Ricken, G., Widhalm, G., Rajky, O., Hainfellner, J. A., \& Birner, P., et al. (2014). PD1 (CD279) and PD-L1 (CD274, B7H1) expression in Primary Central Nervous System Lymphomas (PCNSL). Clinical Neuropathology, 33(1), 42-9. [DOI:10.5414/NP300698] [PMID]

Brahmer, J. R., Tykodi, S. S., Chow, L. Q., Hwu, W-J., Topalian, S L., \& Hwu, P., et al. (2012). Safety and activity of anti-PD-L1 an- tibody in patients with advanced cancer. New England Journal of Medicine, 366(26), 2455-65. [DOI:10.1056/ NEJMoa1200694] [PMID] [PMCID]

Callahan, M. K., \& Wolchok, J. D. (2013). At the bedside: CTLA-4and PD-1-blocking antibodies in cancer immunotherapy. Journal of Leukocyte Biology, 94(1), 41-53. [DOI:10.1189/jlb.1212631] [PMID] [PMCID]

Chapuy, B., Roemer, M. G., Stewart, C., Tan, Y., Abo, R. P., \& Zhang, L., et al. (2016). Targetable genetic features of primary testicular and primary central nervous system lymphomas. Blood, The Journal of the American Society of Hematology, 127(7) 869-81. [DOI:10.1182/blood-2015-10-673236] [PMID] [PMCID]

Chen, B. J., Chapuy, B., Ouyang, J., Sun, H. H., Roemer, M. G., \& Xu, M. L., et al. (2013). PD-L1 expression is characteristic of a subset of aggressive B-cell lymphomas and virus-associated malignancies. Clinical Cancer Research, 19(13), 3462-73. [DOI:10.1158/1078-0432.CCR-13-0855] [PMID] [PMCID]

Ding, W., LaPlant, B. R., Call, T. G., Parikh, S. A., Leis, J. F., \& He, R., et al. (2017). Pembrolizumab in patients with CLL and Richter transformation or with relapsed CLL. Blood, The Journal of the American Society of Hematology, 129(26), 3419-27. [DOI:10.1182/ blood-2017-02-765685] [PMID] [PMCID]

Edwards, J., Wilmott, J. S., Madore, J., Gide, T. N., Quek, C., \& Tasker, A., et al. (2018). CD103+ tumor-resident CD8 ${ }^{+} \mathrm{T}$ cells are associated with improved survival in immunotherapynaïve melanoma patients and expand significantly during anti-PD-1 treatment. Clinical Cancer Research, 24(13), 3036-45. [DOI:10.1158/1078-0432.CCR-17-2257] [PMID]

Gatalica, Z., Snyder, C., Maney, T., Ghazalpour, A., Holterman, D. A., \& Xiao, N., et al. (2014). Programmed cell death 1 (PD-1) and its ligand (PD-L1) in common cancers and their correlation with molecular cancer type. Cancer Epidemiology and Prevention Biomarkers, 23(12), 2965-70. [DOI:10.1158/1055-9965.EPI-140654] [PMID]

Jaffe, E. S., Arber, D. A., Campo, E., Harris, N. L., \& Quintanilla-Fend, L. (2016). Hematopathology e-book. Elsevier Health Sciences. https://books.google.com/ books?id=BKuODAAAQBAJ\&dq

Kantekure, K., Yang, Y., Raghunath, P., Schaffer, A., Woetmann, A., \& Zhang, Q., et al. (2012). Expression patterns of the immunosuppressive proteins PD-1/CD279 and PD-L1/CD274 at different stages of Cutaneous T-Cell Lymphoma (CTCL)/Mycosis Fungoides (MF). The American Journal of Dermatopathology, 34(1), 126-8. [DOI:10.1097/DAD.0b013e31821c35cb] [PMID] [PMCID]

Korfel, A., \& Schlegel, U. (2013). Diagnosis and treatment of primary CNS lymphoma. Nature Reviews Neurology, 9(6), 317-27. [DOI:10.1038/nrneurol.2013.83] [PMID]

Miyasato, Y., Takashima, Y., Takeya, H., Yano, H., Hayano, A., \& Nakagawa, T., et al. (2018). The expression of PD-1 ligands and IDO1 by macrophage/microglia in primary central nervous system lymphoma. Journal of Clinical And Experimental Hematopathology, 58(2), 95-101. [DOI:10.3960/jslrt.18001] [PMID] [PMCID]

Nayak, L., Iwamoto, F. M., LaCasce, A., Mukundan, S., Roemer, M. G., \& Chapuy, B., et al. (2017). PD-1 blockade with nivolumab in relapsed/refractory primary central nervous system and testicular lymphoma. Blood, The Journal of the American Society of Hematology, 129(23), 3071-3. [DOI:10.1182/ blood-2017-01-764209] [PMID] [PMCID] 
Panjwani, P. K., Charu, V., DeLisser, M., Molina-Kirsch, H., Natkunam, Y., \& Zhao, S. (2018). Programmed death-1 ligands PD-L1 and PD-L2 show distinctive and restricted patterns of expression in lymphoma subtypes. Human Pathology, 71, 91-9. [DOI:10.1016/j.humpath.2017.10.029] [PMID]

Preusser, M., Woehrer, A., Koperek, O., Rottenfusser, A., Dieckmann, K., \& Gatterbauer, B., et al. (2010). Primary central nervous system lymphoma: A clinicopathological study of 75 cases. Pathology, 42(6), 547-52. [DOI:10.3109/00313025.2010.5 08786] [PMID]

Turnis, M. E., Andrews, L. P., \& Vignali, D. A. (2015). Inhibitory receptors as targets for cancer immunotherapy. European Journal of Immunology, 45(7), 1892-905. [DOI:10.1002/ eji.201344413] [PMID] [PMCID]

Wolchok, J. D., Kluger, H., Callahan, M. K., Postow, M. A., Rizvi, N. A., \& Lesokhin, A. M., et al. (2013). Nivolumab plus ipilimumab in advanced melanoma. The New England Journal of Medicine, 369, 122-33. [DOI:10.1056/NEJMoa1302369] [PMID] [PMCID]

Yang, X. L., \& Liu, Y. B. (2017). Advances in pathobiology of primary central nervous system lymphoma. Chinese Medical Journal, 130(16), 1973-97. [DOI:10.4103/0366-6999.211879] [PMID] [PMCID]

Zuazo, M., Gato-Cañas, M., Llorente, N., Ibañez-Vea, M., Arasanz, H., \& Kochan, G., et al. (2017). Molecular mechanisms of programmed cell death-1 dependent $\mathrm{T}$ cell suppression: relevance for immunotherapy. Annals of Translational Medicine, 5(19), 385. [DOI:10.21037/atm.2017.06.11] [PMID] [PMCID] 